\title{
Avaliação In Vitro do Potencial Antimicrobiano \\ de Diferentes Materiais Restauradores
}

\author{
Juliane Cristina Ciccone ${ }^{\mathrm{a}}$, Maraísa Palhão Verri ${ }^{\mathrm{b}}$, Maria Fidela de Lima Navarro ${ }^{\mathrm{c}}$, \\ Sérgio Luís Salvador ${ }^{\mathrm{b}}$, Regina Guenka Palma-Dibb \\ ${ }^{a}$ Universidade de São Paulo, Faculdade de Odontologia - Ribeirão Preto, Departamento de \\ Odontologia Restauradora, Av. do Café, s/n, 14040904 Ribeirão Preto - SP, Brasil \\ ${ }^{\mathrm{b}}$ Universidade de São Paulo, Faculdade de Ciências Farmacêuticas de Ribeirão Preto, \\ Departamento de Analises Clínicas Toxicológicas e Bromatológicas, \\ Av. do Café, s/n, 14040-904 Ribeirão Preto - SP, Brasil \\ ${ }^{\mathrm{C}}$ Universidade de São Paulo, Faculdade de Odontologia de Bauru, \\ Departamento de Dentística, Endodontia e Materiais Dentário, \\ Rua Otávio Pinheiro Brisola 9-57, 17012-901 Bauru - SP, Brasil
}

Received: March 10, 2003; Revised: September 29, 2003

\begin{abstract}
The aim of this study was to evaluate the antimicrobial activity of restorative materials - Fuji II LC, Ketac-Fil, Ketac-Molar, Vidrion R, Fuji IX, Ariston pHc, Degufill Mineral, Z100 and Compoglass. For this purpose the agar diffusion test was used determining the bacterial growth inhibition halo over Streptococcus mutans, Streptococcus sobrinus, Staphylococcus aureus and Micrococcus luteus. The materials were prepared and manipulated under aseptic conditions, following the manufacturer instructions. The specimens were immersed in media (Mha and BHIa) that presented the microorganisms. After a $2 \mathrm{~h}$ pre-incubation period, at room temperature the plaques were incubated at $37{ }^{\circ} \mathrm{C}$ for $48 \mathrm{~h}$. After that, the presence or absence of bacterial growth inhibition halo was verified. Vidrion $\mathrm{R}$ and the liquid component of all glass ionomers tested showed antimicrobial activity. However, the resin composite and the "compomer" did not show any antimicrobial activity. In conclusion, only the glass ionomer cement Vidrion R showed antimicrobial activity.
\end{abstract}

Keywords: glass ionomer cement, composite resin, antimicrobial potential, microorganisms

\section{Introdução}

Os materiais restauradores poliméricos apresentam contração de polimerização que pode resultar na formação de fendas na interface dente/material restaurador, e conseqüentemente propiciar a colonização por microrganismos, o que poderia favorecer o aparecimento de cárie secundária ${ }^{1}$. Este problema tem sido identificado como uma das principais causas de insucesso de uma restauração².

Na tentativa de obter materiais restauradores, que previnam a colonização das fendas marginais ${ }^{3}$ e ainda, diminuam a quantidade de bactérias na dentina afetada sob as restaurações ${ }^{4}$, surgiram os materiais com capacidade de liberar flúor e proporcionar algum potencial antimicrobiano, dentre eles, os cimentos ionoméricos, os "compômeros" e as resinas compostas com flúor 5 .
Estes materiais podem atuar de forma benéfica ao substrato dental, possivelmente pela liberação de fluoretos às estruturas adjacentes a restauração $0^{1,6-10}$. Os fluoretos liberados irão participar dos fenômenos de desmineralização e remineralização, podendo atuar diretamente no processo carioso $^{8,11,12}$. Entretanto, essa relação entre a liberação de flúor e a diminuição de microrganismos cariogênicos ainda é controversa. Existem divergências quanto à atividade antimicrobiana destes materiais restauradores, com investigações apresentando resultados favoráveis ${ }^{13-19}$, bem como insatisfatórios ${ }^{10,20,21}$.

Desta forma, o objetivo do presente trabalho foi avaliar in vitro a capacidade de diferentes materiais restauradores, de inibir o desenvolvimento de microrganismos presentes

*e-mail: rgpalma@forp.usp.br 
na cavidade bucal (Streptococcus mutans, Staphylococcus aureus, Micrococcus luteus e Streptococcus sobrinus).

\section{Material e Método}

Foram testados nove materiais restauradores (Tabela 1), com relação a sua capacidade de inibir o desenvolvimento do Streptococcus mutans (ATCC25175), Micrococcus luteus (ATCC941), Staphylococcus aureus (ATCC25923) e Streptococcus sobrinus (cepa de campo). Optou-se pela escolha desses microrganismos, uma vez que, Streptococcus mutans e Streptococcus sobrinus, estão presentes no biofilme dental e na doença cárie, enquanto, que o Micrococcus luteus é um microrganismo indicador sensível aos testes microbiológicos e o Staphylococcus aureus é um microrganismo encontrado em grande número na cavidade bucal, sendo causador de doenças sistêmicas.

Para tal finalidade, os materiais foram manipulados seguindo as instruções do fabricante e inseridos em uma matriz de teflon que apresentava $6 \mathrm{~mm}$ de diâmetro por $2 \mathrm{~mm}$ de espessura. Todos os espécimes $(n=18)$ foram confeccionados sob condições assépticas, para evitar a proliferação

Tabela 1. Materiais restauradores testados.

\begin{tabular}{|c|c|c|c|}
\hline Materiais Restauradores & Tipo & Composição & Fabricantes \\
\hline $\begin{array}{l}\text { Fuji II LC } \\
\quad \# 0209 \\
13.2: 1.0\end{array}$ & $\begin{array}{l}\text { Cimento de ionômero } \\
\text { de vidro modificado } \\
\text { por resina composta }\end{array}$ & $\begin{array}{l}\text { P: alumínio-fluorsilicato de vidro. } \\
\text { L: água, ácido poliacrílico e } \\
\text { HEMA }\end{array}$ & $\begin{array}{l}\text { GC corporation } \\
\text { Tokyo, } 174-8585 \\
\text { Japan }\end{array}$ \\
\hline $\begin{array}{c}\text { Fuji IX } \\
\# 010571 \\
3.6: 1.0\end{array}$ & $\begin{array}{l}\text { Convencional- alta } \\
\text { viscosidade }\end{array}$ & $\begin{array}{c}\text { P:alumínio-fluorsilicato de vidro, } \\
\text { ácido poliacrílico. L: água, ácido } \\
\text { poliacrílico , ácido tartárico, ácido } \\
\text { carboxílico polibásico }\end{array}$ & $\begin{array}{l}\text { GC corporation } \\
\text { Tokyo, } 174-8585 \\
\text { Japan }\end{array}$ \\
\hline $\begin{array}{l}\text { Vidrion R } \\
\quad \# 00 \mathrm{E}\end{array}$ & $\begin{array}{l}\text { Convencional- baixa } \\
\text { viscosidade }\end{array}$ & $\begin{array}{l}\text { P: Na-Ca-Al-fluorsilicato, Ba- } \\
\text { sulfato, ácido poliacrílico, } \\
\text { pigmento. L: ácido tártarico, } \\
\text { água deionizada. }\end{array}$ & $\begin{array}{l}\text { SSWHITE- Senador } \\
\text { Alencar, 160, Rio de } \\
\text { Janeiro - RJ, Brasil, } \\
\text { CEP: 20921-430 }\end{array}$ \\
\hline $\begin{array}{c}\text { Ketac Molar } \\
\text { \#FW0047716 } \\
\text { 3.0:1.0 }\end{array}$ & $\begin{array}{l}\text { Convencional- alta } \\
\text { viscosidade }\end{array}$ & $\begin{array}{l}\text { P: Ca-Al-La fluorsilicato de vidro, } \\
\text { ácido acrílico, ácido maleico, } \\
\text { copolímeros. L: ácido acrílico, } \\
\text { ácido maleico copolímeros, } \\
\text { ácido tartárico e água. }\end{array}$ & $\begin{array}{l}\text { SPE-Premier Corp. } \\
\text { Norristown, PA } 19404\end{array}$ \\
\hline $\begin{array}{c}\text { Ketac }- \text { fil } \\
\text { \#FW0050630 } \\
\text { 3.2:1.0 }\end{array}$ & Convencional & $\begin{array}{c}\text { P: St-Al-La fluorsilicato glass. L: } \\
\text { ácido tártarico, ácido copolímero } \\
\text { e água. }\end{array}$ & $\begin{array}{l}\text { ESPE-Premier Corp. } \\
\text { Norristown, PA } 19404\end{array}$ \\
\hline $\begin{array}{l}\text { Z100 } \\
\text { \#9RG }\end{array}$ & Resina Composta & Bis-GMA, TEGDMA & $\begin{array}{l}\text { 3M St. Paul, } \\
\text { MN } 55144 \text { USA }\end{array}$ \\
\hline $\begin{array}{l}\text { Ariston Phc } \\
\text { \#A16397 }\end{array}$ & Resina Composta & $\begin{array}{l}\text { Dimetacrilato, vidro alcalino, BA- } \\
\text { Al-fluorsilicato de vidro, itérbio, } \\
\text { trifluoreto e dioxido de silicone. }\end{array}$ & $\begin{array}{l}\text { Vivadent Ets. FL-9494 } \\
\text { Schaan/ } \\
\text { Liechtenstein }\end{array}$ \\
\hline $\begin{array}{l}\text { Degufill } \\
\text { Mineral } \\
\# 303-2\end{array}$ & Resina Composta & $\begin{array}{c}\text { HEMA, etanol, água, metacrilato } \\
\text { de Bis-GMA, dioxido de silicone, } \\
\text { B-Al-Ba silicato, Ca-fosfato- } \\
\text { fluoreto-apatita }\end{array}$ & $\begin{array}{l}\text { Degussa-Hüls AG } \\
\text { Postfach } 1364 \\
\text { D-63403 Hanau }\end{array}$ \\
\hline $\begin{array}{l}\text { Compoglass } \\
\text { \#B00070 }\end{array}$ & $\begin{array}{l}\text { Resina modificada com } \\
\text { poliácido }\end{array}$ & $\begin{array}{l}\text { Dimetacrilato, tetraetileno glicol } \\
\text { dimetacrilato, e ácido cicloalifático } \\
\text { dicarboxilico dimetacrilato, } \\
\text { trifluoreto itérbio, Ba-Al- } \\
\text { fluorsilicato de vidro e óxido. }\end{array}$ & $\begin{array}{l}\text { Vivadent Ets. FL-9494 } \\
\text { Schaan/Liechtenstein }\end{array}$ \\
\hline
\end{tabular}


microbiana indesejável quando da incubação no meio de cultura.

Previamente a confecção dos corpos-de-prova, foi preparada placas de Petri $(100 \mathrm{~mm} / 15 \mathrm{~mm})$, autoclavadas a $120{ }^{\circ} \mathrm{C}$ por $20 \mathrm{~min}$ com $10 \mathrm{~mL}$ do meio de cultura. Os meios de cultura usados foram: Agar infusão de cérebro e coração (BHIa-Difco) para o microrganismo $S$. mutans e $S$. sobrinus, devido a esses requererem um meio mais nutritivo para seu desenvolvimento e proliferação, e o meio Muller Hinton Agar (Mha-Difco) para M. luteus e S. aureus. Em seguida, os espécimes foram dispostos sobre a placa e despejou-se sobre os mesmos uma camada constituída por 5 $\mathrm{mL}$ do meio de cultura, acrescido de uma suspensão padronizada dos microrganismos indicadores baseados na metade da escala 1 de Mac Farland.

Além de testar o material já manipulado, realizaram-se os mesmos testes com os componentes (pó e líquido) dos cimentos ionoméricos ativados quimicamente. Para tanto, foi empregada a técnica antimicrobiana do poço, que consiste na confecção de pequenos orifícios (6 $\mathrm{mm}$ de diâmetro por $4 \mathrm{~mm}$ de profundidade) na placa de Petri, seguida da inserção do material em quantidades suficientes para o seu total preenchimento. Prévio a realização deste teste, a placa de Petri foi preparada da mesma forma e com os mesmos microrganismos indicadores descritos acima.

Após a colocação dos espécimes/pó/líquido, as placas permaneceram em pré-incubação por $2 \mathrm{~h}$, à temperatura ambiente e em seguida foram incubadas a $37^{\circ} \mathrm{C}$ por $24 \mathrm{~h}$ em aerobiose (M. luteus e $S$. aureus) e por $48 \mathrm{~h}$ em microaerofilia (S. mutans e S. sobrinus). A seguir, com auxílio de uma lupa esterioscópica (Nikon) com $40 \times$ de aumento, foi verificada a presença ou ausência de zonas de inibição bacteriana em torno dos espécimes, permitindo uma análise qualitativa quanto a capacidade antimicrobiana dos materiais restauradores testados.

Para todos os materiais, foram realizados experimentos em duplicata, para os quatro microrganismos empregados. Adotou-se tal metodologia pois se tratam de cepas-padrão, que proporcionam resultados confiáveis com apenas duas repetições de cada material, sendo assim suficiente para a análise dos resultados.

\section{Resultados}

Os resultados do presente estudo permitiram verificar que, apenas o cimento ionomérico Vidrion $\mathrm{R}$ apresentou zona de inibição bacteriana sobre as quatro bactérias testadas, evidenciando bom potencial antimicrobiano.

As resinas compostas com e sem flúor em sua composição, bem como o "compômero", não apresentaram halo de inibição bacteriana sobre os microrganismos indicadores, não tendo exibido nenhum potencial antimicrobiano.

Ao avaliar separadamente os componentes, pó e líqui- do, dos materiais quimicamente ativados, verificou-se halo de inibição bacteriana em torno do líquido de todos os materiais, enquanto para o pó, não se observou atividade antimicrobiana.

\section{Discussão}

A cárie secundária é uma das principais causas para o insucesso de uma restauração ${ }^{2}$, pois ocorre na interface dente/material restaurador ocasionada pelo acúmulo de biofilme bacteriano nessa região ${ }^{1}$. Para reduzir a freqüência e severidade deste problema vêm se buscando materiais que apresentem potencial antimicrobiano.

$\mathrm{O}$ presente estudo observou que dentre os cimentos ionomêricos testados, apenas o Vidrion $\mathrm{R}$, apresentou propriedades antimicrobianas. Provavelmente, tal fato se deve as diferentes composições apresentadas por estes materiais (presença ou ausência de óxidos ${ }^{16}$, tipo de ácidos presentes em sua composição ${ }^{23}$ ) e a capacidade de liberação de fluoretos ${ }^{6}$. Os ionômeros liberam quantidades de íons flúor que diferem de acordo com suas características individuais, sendo que, em alguns materiais ocorre uma grande liberação, o que pode comprometer sua solubilidade e desintegração $^{24}$.

Apesar dos resultados desfavoráveis obtidos quanto à ação antimicrobiana dos outros cimentos ionoméricos testados, esses materiais não devem ser descartados da prática odontológica, visto que, o flúor liberado pode proporcionar um melhor potencial de remineralização do esmalte adjacente a restauração ${ }^{8}$, bem como, promover a formação de uma camada intermediária de carbonato apatita fluoretada, formada após 2-4 h de inserção do material ${ }^{25}$. Essa camada tem fundamental importância clínica, uma vez que, por ser menos solúvel, resulta em uma efetiva barreira à dissolução do esmalte e da dentina pelo ácido lático ${ }^{26}$.

Da mesma forma, o "compômero" e as resinas compostas avaliados no presente estudo, não foram capazes de levar a formação de halos inibição bacteriana. Tal fato, pode estar relacionado à ausência de íons flúor na composição do material ou a diferença na quantidade de fluoretos liberados. A liberação destes íons pode ser influenciada pela presença ou ausência de reação de geleificação (ácido-base), bem como, pela composição química do material27 ${ }^{27}$, sendo verificado que o cimento ionomérico convencional libera significantemente maior quantidade de flúor do que as resinas compostas, os "compômeros" e os cimentos de ionômero de vidro modificado por resina ${ }^{10}$.

Quando os componentes, pó e líquido, que foram analisados separadamente, pode-se observar que apenas os componentes líquidos de todos os ionômeros apresentaram halos de inibição. Este resultado pode ser decorrente da presença de ácidos, que reagem com os componentes do pó, e de agentes antimicrobianos, que não permitem a multiplica- 
ção de microrganismos na solução.

Visto os resultados observados neste estudo, futuras investigações tornam-se necessárias para estabelecer a quantidade de íons flúor a ser liberada ao meio bucal, que promova uma efetiva inibição dos microrganismos cariogênicos, além de verificar a real atividade desses materiais, sob diferentes condições laboratoriais, que mimetizam o complexo sistema in vivo.

\section{Conclusões}

Sob as condições deste estudo in vitro, pode-se concluir que:

O Vidrion R apresentou capacidade antimicrobiana sobre os tipos de bactérias empregadas neste estudo. Os componentes líquidos dos ionômeros analisados foram capazes de exercer atividade antimicrobiana sobre todos os microrganismos indicadores. As resinas compostas e o "compômero", não apresentaram capacidade de inibição bacteriana.

\section{Referências Bibliográficas}

1. Kidd, E.A.; Toffenetti, F.; Mjör, I.A. International Dental Journal, v. 42, n. 3, p. 127-138, 1992.

2. Friedl, K.H.; Hiller, K.A.; Schmalz, G. Operative Dentistry. v.20, n. 1, p. 34-38, 1995.

3. Tobias, R.S. International Endodontic Journal, v. 21, n.2, p. 155-160, 1988.

4. Weerheijm, K.L.; Kreulen, C.M.; Soet, J.J.; Groen, H.J.; Van Amerongen, W.E. Caries Research, v. 33, n.2, p. 130134, 1999.

5. Beockh, C.; Schumacher, E.; Podbielski, A.; Haller, B. Caries Research, v. 36, n. 2, p. 101-107, 2002.

6. Araujo, F.B.; Garcia-Godoy, F.; Cury, J.A.; Conceição, E.N. Operative Dentistry, v. 21, n. 5, p. 185-190, 1996.

7. Donly, K.J.; Nelson, J.J. Journal of Dentistry for Children, v. 64, n. 4, p. 249-250, 1997.

8. Forss, H.; Seppä, L. Advances in Dental Research, v. 9, n. 4, p. 389-393, 1995.

9. Strother, J.M.; Kohn, D.H.; Dennison, J.B.; Clarkson, B.H.
Dental Materials, v. 14, n. 2, p. 129-136, 1998.

10. Yap, A.U.J., Khor, E.; Foo, S.H. Operative Dentistry, v. 24, n. 5, p. 297-305, 1999.

11. Navarro, M.F.L.; Pascoto, R. Cimento de Ionômero de Vidro. Artes Médicas, São Paulo,p. 179, 1998.

12. Smales, R.J.; Gao, W. Journal of Dentistry, v. 28, n. 4, p. 249-256, 2000.

13. Forss, H. et al. Caries Research, v. 25, n. 6, p. 454-458, 1991.

14. Gillgrass, T.J.; Millett, D.T.; Creanor, S.L. Journal of Dentistry, v. 27, n. 6, p. 455-461, 1999.

15. Ortendahl, T.; Thilander, B. Svanberg, M. American Journal of Orthodontics and Dentofacial Orthopedics, v. 112, n. 3, p. 271-274, 1997.

16. Scherer, W.; Lippman, N.; Kaim, J. Operative Dentistry, v. 14, n. 2, p. 77-81, 1989.

17. Svanberg, M.; Krasse, B.; Ornerfeldt, H.O. Caries Research, v. 24, n.2, p. 133-136,1990.

18. Svanberg, M.; Mjör, I.A.; Orstavik, D. Journal of Dental Research, v. 69, n. 3, p. 861-864, 1990.

19. Botelho, M.G. Caries Research, v. 37, n. 2, p. 108-114, 2003.

20. Sanders, B.J.; Gregory, R.L.; Moore, K.; Avery, D.R. Journal of Oral Rehabilitation, v. 29, n. 6, p. 553-558, 2002.

21. Klimek J.; Ganss, C.; Bünker, H. Caries Research, v. 31, n. 4, p. 281-328, 1997.

22. Van Dijken, J.W.; Kalfas, S.; Litra, V.; Oliveby, A. Caries Research, v. 31, n. 5, p. 379-383, 1997.

23. Tam, L.E.; Chan, G.P-L; Yim, D. Operative Dentistry, v. 22, n. 1, p. 4-14, 1997.

24. Bertacchini, S.M.; Abate, P.F.; Blank, A.; Baglieto, M.F.; Macchi, R. L. Quintssence International, v. 30, n. 3, p. 193-197, 1999.

25. Geiger, S.B. Weiner, S. Dental Materials, v. 9, n. 1, p. 3336, 1993.

26. Brown, W.E.; Gregory, T.M.; Chow, L.C. Caries Research, v. 11, n. 1, p. 118-141, 1977.

27. Vermeersch, G.; Leloup, G; Vreven, J. Journal of Oral Rehabilitation, v. 28,n. 1, p. 26-32, 2001. 